\title{
Tool Wear and Surface Roughness in Hard Turning of Stainless Steel 316 Using Tungsten Carbide Tool
}

\section{تآكل العدة وخشونة السطح فى عمليات الخراطة الصعبة للصلب الأى لا يصدأ 316 باستخام العداد الكربياية}

\author{
Ali Abdelaziz ${ }^{1}$, Ahmed Elkaseer ${ }^{2}$, Ahmed Nassef ${ }^{3}$ \\ ${ }^{1}$ Northern Workshop, Port Said Shipyard, Suez Canal Authority. \\ Email: aliabdelaziz2006@yahoo.com \\ ${ }^{2}$ Assistant Prof. of Production Eng., Faculty of Eng., Port Said University. \\ Email: elkaseeram@gmail.com \\ ${ }^{3}$ Prof. of Production Eng., Faculty of Eng., Port Said University. \\ Email: nassef12@hotmail.com
}

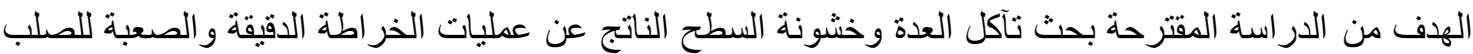

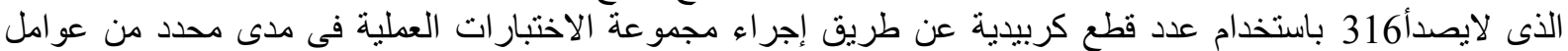

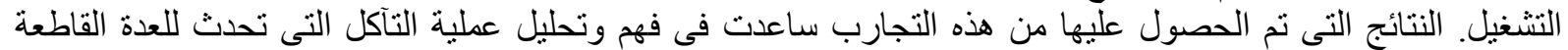

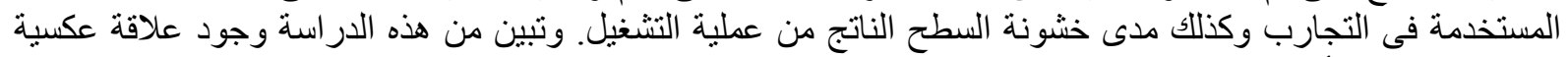

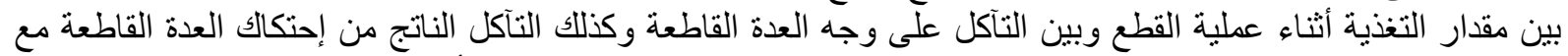

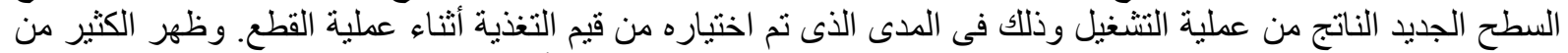

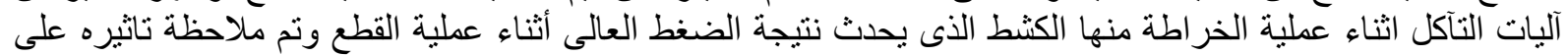

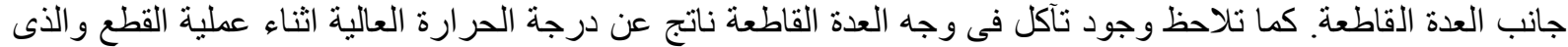

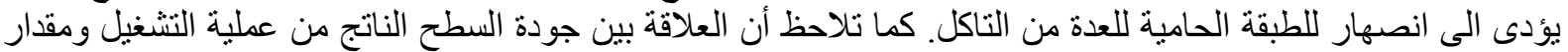
التخذية أثناء عملية القطع فى عمليات الخر اطة الدقيقة علاقة غير خطية على عكس ما يحدث فى عمليات الخر اطة التقليدية.
\end{abstract}

\begin{abstract}
The aim of the present study was to investigate tool wear and surface roughness generation in precision hard turning of stainless steel 316 using tungsten carbide tool. A set of turning tests were carried out under a range of cutting parameters with carbide insert tools. The data obtained from these experiments helped in analyzing and understanding the tool wear phenomena and generated surface roughness during the cutting process. These results showed an inverse relationship between the feed rate and the exhibited flank wear and crater wear over the applied range of feed rate. However, multiple wear mechanisms revealed after the turning tests, namely abrasion mechanism due to high pressure was observed on the flank of the tool, while diffusion mechanism exhibited on the tool face due to the high cutting temperature and led to crater wear. In additions, in contrast to the conventional turning process, nonlinear relationship was observed between the feed rate and surface roughness in case of precision turning operation.
\end{abstract}

\section{Keywords}

Hard turning, crater wear, flank wear, carbide tool, surface roughness

\section{Introduction}

Hard turning refers to the process of utilizing single point tool to machine materials that have high strength, corrosive resistance, toughness, and wear resistance [1], which so-called hard-to-cut materials. This technology is considered a cost- effective and reliable alternative to grinding process. However, in order to circumvent such tough machining circumstances, appropriate cutting conditions have to be applied in order to enable hard turning to deliver very fine machined surfaces [2]. Besides, it has also 
been reported that the resulting machining time reduction is as high as $60 \%$ in hard turning [3]. The turning of hard-to-cut materials is used in many applications such as gears, shafts, bearings, cams, forgings, dies and molds, which significantly reduce the manufacturing costs, lead times and improve overall product quality [3]. This is especially achievable when super-hard cutting tool materials, such as cubic boron nitride (CBN), ceramics and tungsten carbides, are commercially available in the market. However, the cutting tools required for hard turning are relatively expensive as compared to grinding operations and hence there is a need to investigate the tool life to assure the economic justification for hard turning. Tool wear problem is a challenge issue that still needs addressing. This is because of its side effects on the tool life, the machined surface and in turn its effects on increasing the entire cost of the machining process [4]. However, one can argue that the main barrier to further development of the hard turning process is the lack of full scientific understanding of the process. In particular, the influence of the applied cutting conditions on matters such as cutting regime, generated surface and tool wear has not been fully examined yet. Therefore, there is a real need to examine the process conditions and to address their influence on the process outcomes, especially tool wear and resultant surface roughness and thus optimizing the process to achieve the best possible performance. In this context, the aim for this paper is conduct a series of experimental trials to examine the influence of the cutting parameters on the machinability of hard-tocut materials in terms of tool wear and obtainable surface quality.

This paper is organized as follows. First a review of related work is presented. Secondly the experimental set-up is described, including a description of workpiece material, machine setup, applied cutting conditions and measuring instrumentation. Thirdly, the obtained results are discussed focusing on the relationship between the cutting tool wear (flank wear - crater wear) and feed rates. Also the effect of the applied feed rate and surface quality is reported. Finally the paper summaries with some conclusions drawn based on the results and discussions.

\section{Related Work}

Many researchers have investigated the hard-turning operation aiming at identifying the optimum conditions that enable the best possible performance of the process.

Huang et. al., [1] studied the exhibited main wear patterns in hard turning using CBN tool. In particular, crater wear, flank wear, notching, cracks, and micro chipping were examined. The authors found that these wear patterns depended on the type of the tool used and the workpiece material composition. Also the authors concluded that the cutting conditions play an important rule at changing the wear pattern. They also found that the flank wear is considered as tool life criterion.

Wang et. al., [4] carried out an experimental study to assess hard turning process with $\mathrm{CBN}$ tool. It was found that the wear on the edge of the cutting tool occurred due to a combination of high temperature, high stresses and perhaps chemical reactions. More than one wear mechanism can be found at the same time at the cutting operation. However, flank and crater wear are the most important wear pattern in hard turning operation.

$\mathrm{Xu}$ et. al., [5]conducted a series of turning experimental trials on steel AISI 1215 using both coated and uncoated carbide insert on a CNC turning machine. The two cutting inserts had the same specs except the coating type and the same cutting condition used. Results founded from experiments explained the relationship between flank wear and the cutting length. The results illustrated that flank wear increased with increasing the cutting length but with coating the 
expansion of insert flank wear will be much lower than uncoated one.

Motorcu [6] investigated experimentally tool life performance and wear mechanisms of various cutting tools under different cutting conditions. The results of these experiments showed the decrease of tool life after the cutting speed increased for all cutting tools. It was observed that the major wear form appeared was flank wear, crater wear and nose deformation. Also the feed rate found had a great effect on tool life.

Thamizhmanii et. al., [2] observed significant effect of cutting tool flank wear on the new machined surface quality. Also, the authors figured out the parameter that increase the flank wear, especially the cutting temperature and the contact between the cutting tool and the work piece. In additions, the cutting speed found to have noticeable influence on the tool flank wear pattern.

Bingul and Kacal [7] found that tool wear has a great effect on the final geometrical dimension of the workpiece. Besides, flank wear considered as the most important tool wear type which should take the priority in tool wear measurement and classifications.

Also it was observed that the cutting feed rate has a significant effect on surface roughness. However, cutting speed found had less influence on surface roughness and the crater wear occurred due to sliding motion of the chip on the tool face.

Caixu et. al., [8] studied the generation mechanism of damaged layer on machined surface, the thermal and mechanical effects due to the coupling between the cutting tool and the work piece during the hard cutting operation. The authors found that these effects can cause serious quenching effect on new machined surfaces in hard turning operation and then damaged layer could be generated.

Kaçaland and Yıldırım [9] carried out a series of experiments to evaluate the tool wear, wear mechanisms and surface roughness. More attention was given to the generated surface quality after machining. It was concluded that when the right cutting conditions was chosen in turning a hard material a mirror surface finish can be achieved. However, the increase of the cutting speed increased the tool flank wear.

\section{Experimental Setup}

\subsection{Workpiece Material}

The workpiece material selected for this study was stainless steel 316 , which was chosen for its wide industrial applications especially when the products subject to sever environmental conditions [10]. The workpiece material was assessed using Spectro-lab (LAV L7) [11] to determine its chemical compositions, see Table 1 for the identified chemical compositions of the workpiece material. Also, the hardness of the material was quantified using ultra-sonic hardness tester, Sonohard [12]. The hardness was measured five times and an average of $170 \mathrm{HV}$ was determined. However, it is worth stressing that although the hardness is not such high, stainless steel 316 is considered hard-to-cut material, and its machining operation is still a challenge issue to be addressed. This is can be explained as machining of such material is associated with very tough cutting condition due to the high strength, corrosive resistance, toughness, and wear resistance which in turn lead to high wear of the cutting tool, and the turning process of this material is categorized as hard turning operation[10].

Table 1: Chemical composition of stainless-steel 316 (in weight percent)

\begin{tabular}{|l|l|l|l|l|l|l|l|}
\hline C & MN & SI & Cr & Co & Ni & Mo & Fe \\
\hline $\mathbf{0 . 0 4}$ & $\mathbf{0 . 9 5}$ & $\mathbf{0 . 5}$ & $\mathbf{1 3 . 5}$ & $\mathbf{0 . 1 9}$ & $\mathbf{1 0}$ & $\mathbf{2 . 2}$ & $\mathbf{7 3 . 9}$ \\
\hline
\end{tabular}

\subsection{Machining Set-up}

To examine the machinability of stainless steel 316, seven sets of experiments were carried out with different machining conditions. In particular, the machinability in terms of tool wear and surface roughness were investigated by 
carrying out longitudinal machining tests on a precise three axis $\mathrm{CNC}$ turning machine, Fig.1.
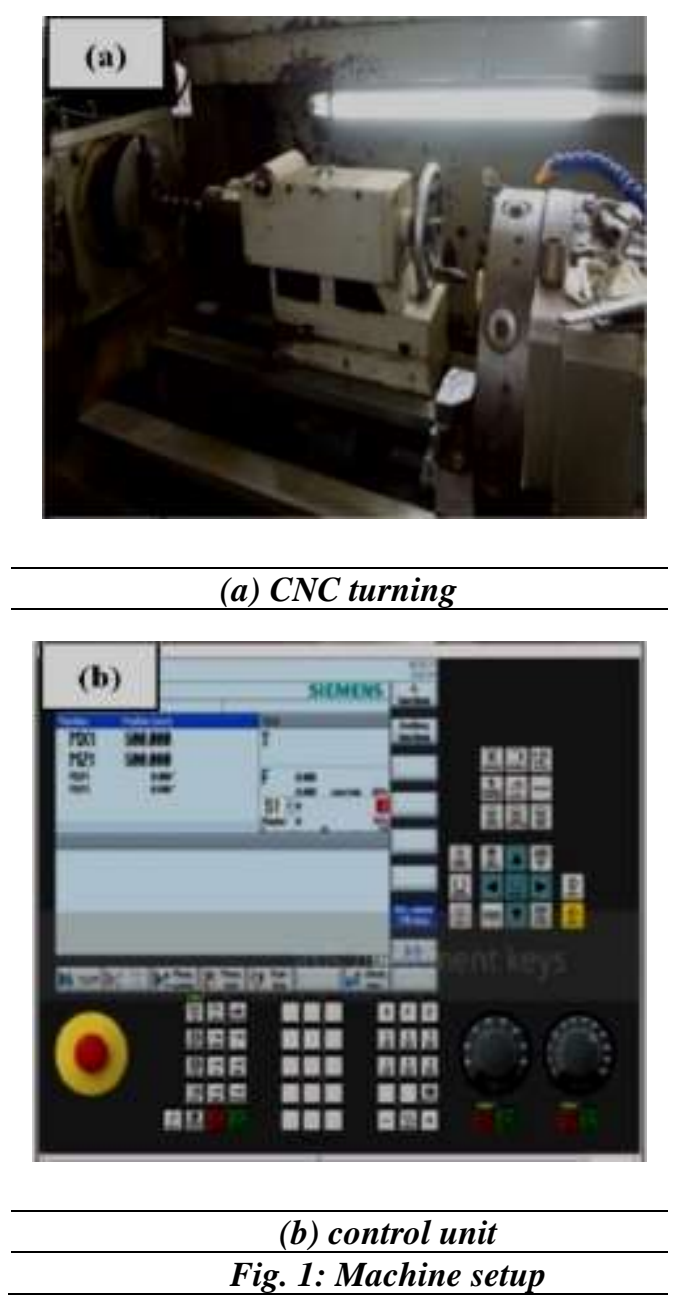

The selected cutting tool used for this experiment was a right hand CNC turning tool. Tungsten carbide insert, SECO (VBMT 1604008 TP3000), was employed that had $0.8 \mathrm{~mm}$ nose radius. Because of small feed rates $(0.01$ to $0.07 \mathrm{~mm} / \mathrm{rev})$ used in these experiments, small depth of cut $(0.1 \mathrm{~mm})$ and the high cutting speed $(150 \mathrm{~m} / \mathrm{min})$, high grade inserts were used which are suitable for machining very hard material under these conditions.

Prior to the cutting tests, each cutter was imaged using an optical microscope to measure approximately the radii of the cutting edges. The cutting edge radius was assessed using Catia software (Catia v5 2d viewer) after conducting the necessary calibration as shown in Fig. $2(a, b)$. The value of the edge radius obtained equal $0.04 \mathrm{~mm}$.

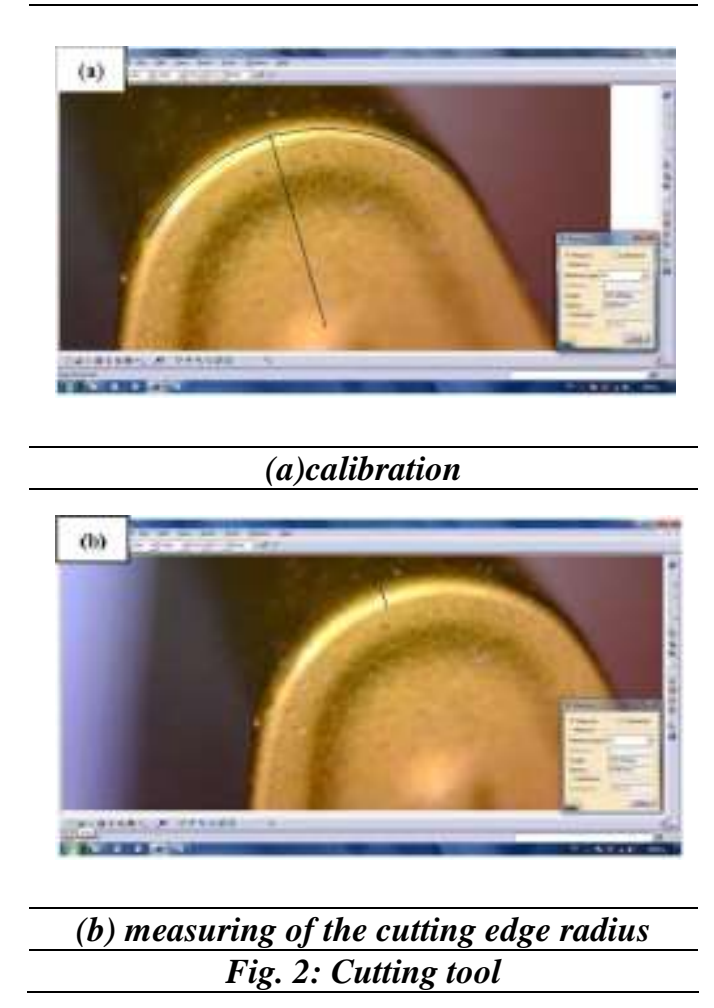

\subsection{The Cutting Conditions}

The experiment was repeated seven times with changing feed rate value on seven different workpieces. The undeformed chip thickness was controlled by varying the feed rate per revolution, and thus to achieve values in the vicinity of the average cutting edge radius, in particular 10 to $70 \mu \mathrm{m} / \mathrm{rev}$ with a step of $10 \mu \mathrm{m}$, for which the best surface roughness is expected. The other cutting parameters used in the trials were one level of cutting speed, $900 \mathrm{rpm}$ equivalent to $150 \mathrm{~m} / \mathrm{min}$ and one level of axial depth of cut, $100 \mu \mathrm{m}$.

\subsection{ExperimentalProcedure}

To carry out the machining tests, workpiece parts were machined with the dimensions as shown in Fig. 3. However, evaluation of crater wear and flank wear were chosen to quantify the tool wear because of their significant influence on the performance of the turning process and especially on the resulting surface roughness. To investigate the effects of these two tool parameters on the machine, 
a new experimental setup was designed and implemented as shown in Fig. 3. It allows the cutting conditions to be maintained unchanged during the trials as there is no need to take off the cutters for offline inspections. The adopted procedure to investigate experimentally the tool wear in hard turning includes the following steps. First, after machining complete longitudinal pass of material, the cutter was cleaned using pressurized air for few sec. Then, two digital microscopes with optical magnifications up to $500 \mathrm{X}$ and $800 \mathrm{X}$ were employed to image the flank and face of the cutter and thus to judge the flank and crater wear, respectively. To inspect the crater and flank wear of the cutter, the measurement functions of the microscope software was used as shown in Fig.4.

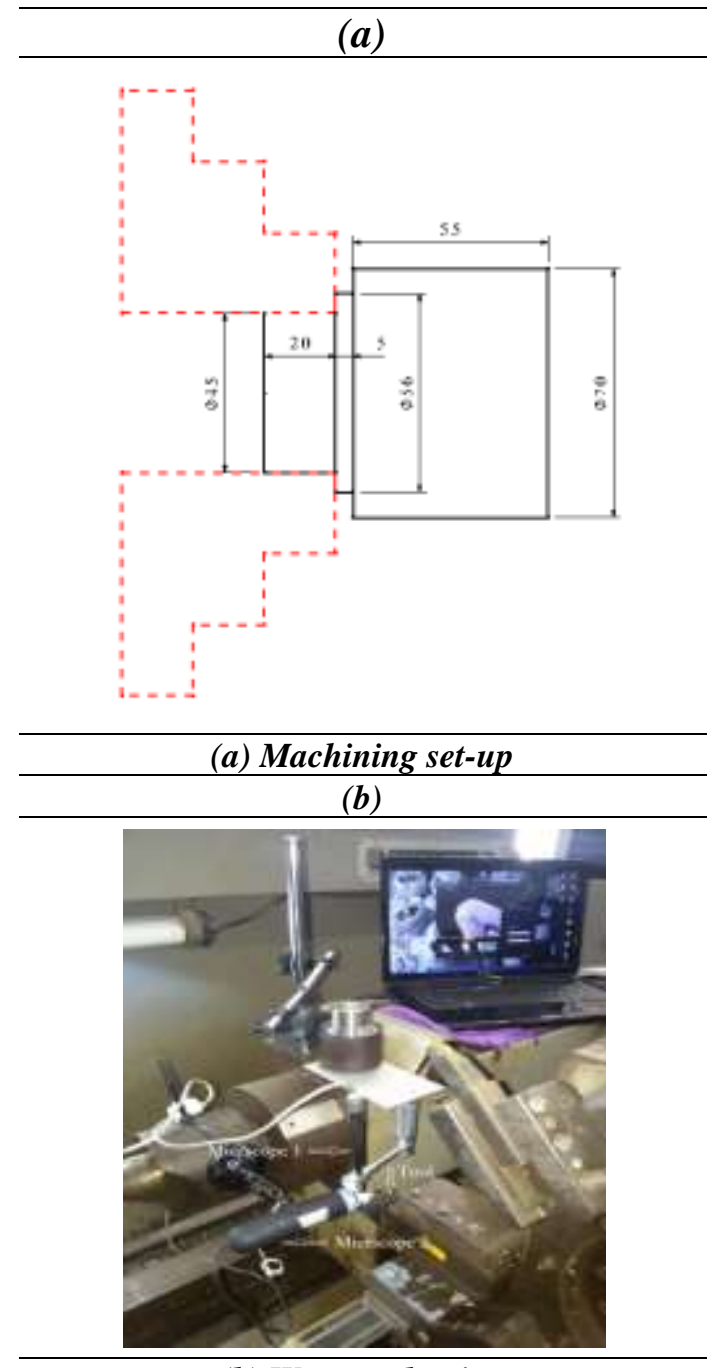

(b) Wear evaluation

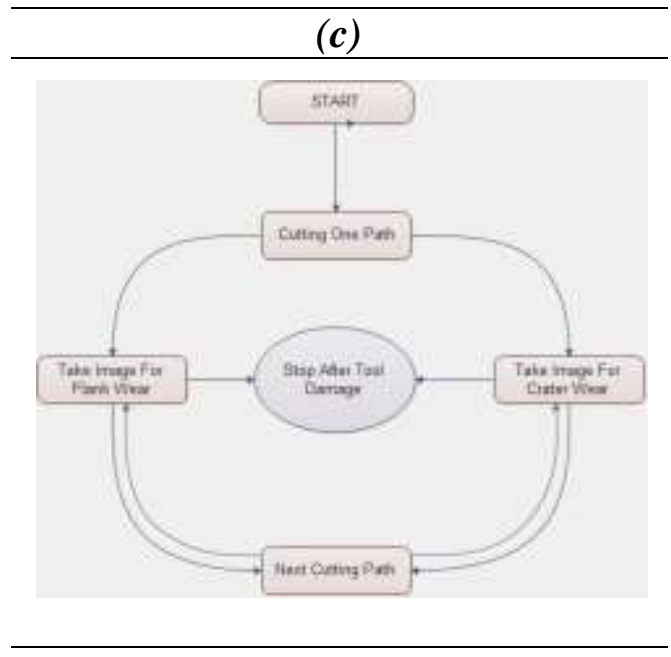

(c) machining procedure

Fig. 3: Experimental setup and plan

\subsubsection{Wear Evaluation}

To measure wear of the cutting tool, map window GIS software was used. Fig. 4 depicts some of the software capabilities employed to assess the tool wear.

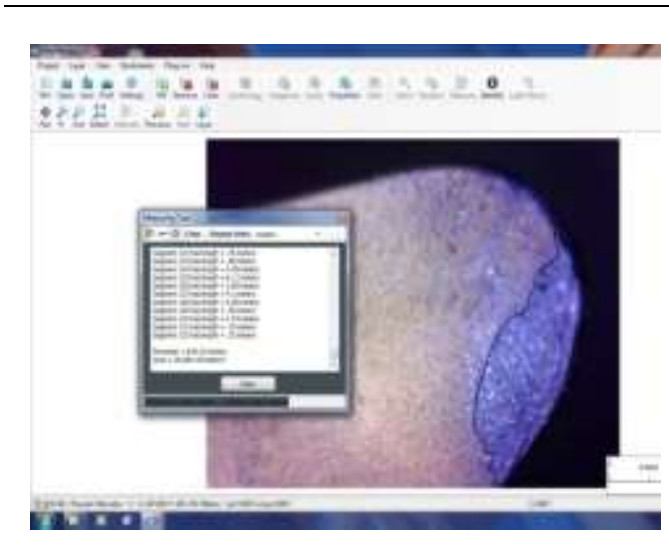

Fig. 4: Map window GIS software [14]

\subsubsection{Roughness Measurement}

Roughness tester, Hommel Tester T500 as shown in Fig. 5, was used to measure the resultant surface roughness. $4.8 \mathrm{~mm}$ standard tracing length and 0.8 cutoff were used. The roughness average, Ra, was evaluated. 


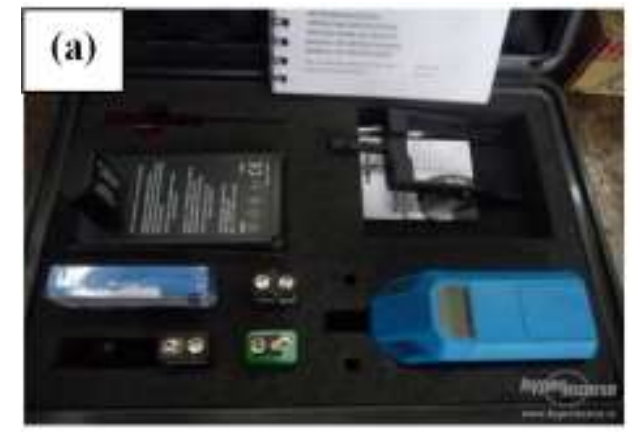

Fig. 5: Roughness measurement Hommel Tester T500 [16]

\section{Results and Discussions}

This section presents discussions of the obtained results that involved the results of the crater wear followed by flank wear results and the resultant surface roughness.

\subsection{Crater Wear}

Fig. 6 shows a collection of captured images of tool crater wear at different cutting conditions. In particular, two different pictures, at each set of applied conditions, were taken. First picture presents the minimum crater wear exhibited finishing the first cutting path of $50 \mathrm{~mm}$, while the second picture illustrates the maximum crater wear, when the tool considered lasted, was also captured.

The most significant tool wear's mechanism when cutting hard materials is diffusion where the temperature along the tool-chip interface can reach as high as $1000^{\circ} \mathrm{C}$.This mechanism is the major reason for the crater wear happened in the tungsten carbide tools used in the experiments. In this mechanism diffused particles transfer from tool to flowing chip and vice versa. These particles also carried away by the flow of chip-material along the tool-chip interface. The repetition of this process causes crater wear. This crater wear gradually becomes deeper with time, resulting in a larger positive rake angle, weakening of the tool tip, causing the failure of the cutting edge [13].

Fig. 7 shows the relationship between the cutting length and the detected crater wear at different feed rate. Based on the results obtained, it is not so difficult to see inverse relationship between the crater wear and feed rate. In particular, smaller feed rate causes higher wear rate when the other parameters kept constant this resulted from high temperature generated at toolchip interface which causes diffusion for chip and particles from the cutting insert as a result for small feed rate also a built up edge happened in conjunction with diffusion mechanism Fig. 8 but when feed rate increased the generated heat temperature decreased relatively. As a result, one can conclude that the maximum tool life occurred at feed rate of 0.07 $\mathrm{mm} / \mathrm{rev}$.

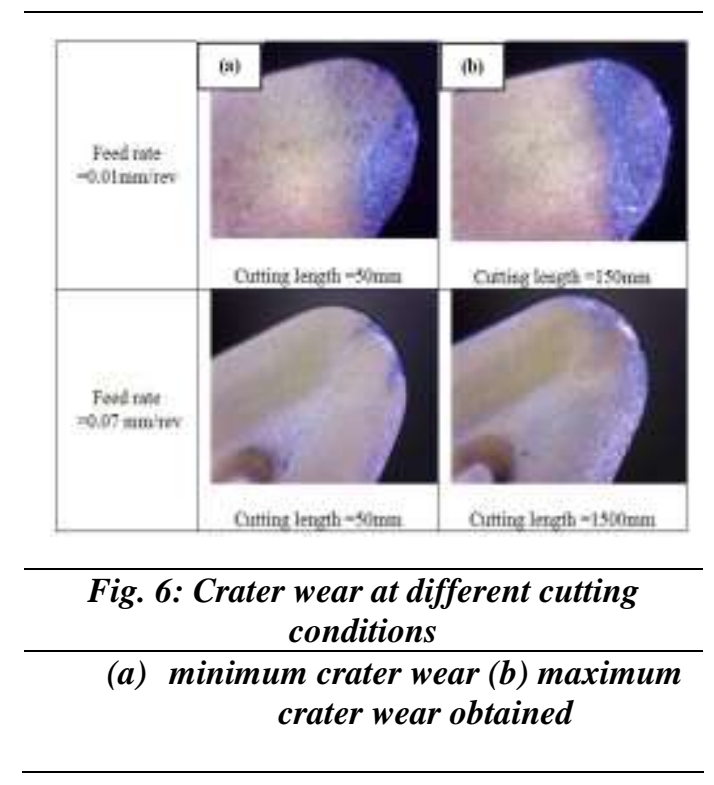



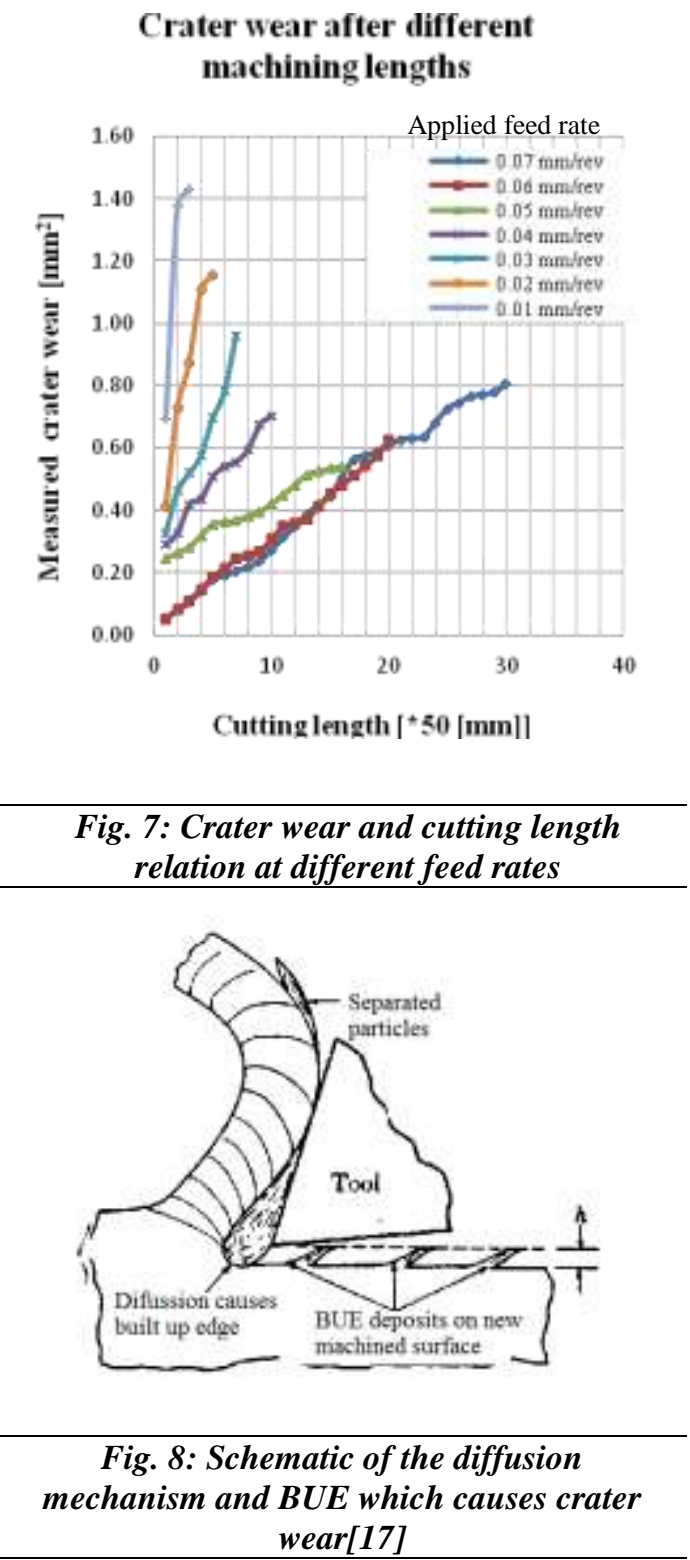

\subsection{Flank wear}

Fig. 9 shown the flank wear detected at the end of first and last machining trial, while, Fig. 10 compare between the typical flank wear and the obtained flank wear after tool lasted. Also Fig. 11 and Fig. 12 illustrate the relationship between the cutting length and the obtained flank wear and maximum flank wear, at different cutting conditions. From the results, it was observed that the flank wear increased with the decrease of feed rate and also the life time of the tool reduced. Besides, it was observed that the maximum flank wear occurred at feed rate $0.01 \mathrm{~mm} / \mathrm{rev}$ and after $150 \mathrm{~mm}$ cutting length but when the value of feed rate increased to $0.02 \mathrm{~mm} / \mathrm{rev}$ flank wear started to decrease and the tool lasted after $250 \mathrm{~mm}$ cutting length. After finishing the seven sets of experiments the last one with feed rate $0.07 \mathrm{~mm} / \mathrm{rev}$ and $1500 \mathrm{~mm}$ (50mm cutting length $* 30$ path) cutting length had the best life time and the minimum flank wear. It is worth emphasizing that for flank wear abrasion was the dominant mechanism due to high pressure at low values of applied feed and depth of cut.

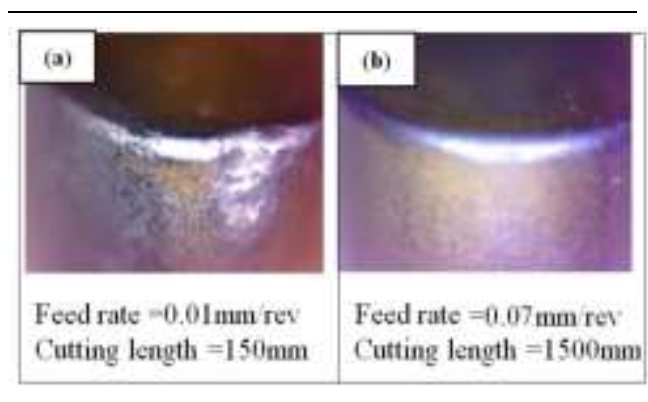

Fig. 9: Flank wear at different feed rates (a) flank wear at Feed rate $=0.01 \mathrm{~mm} / \mathrm{rev}$ (b) flank wear at Feed rate $=0.07 \mathrm{~mm} / \mathrm{rev}$
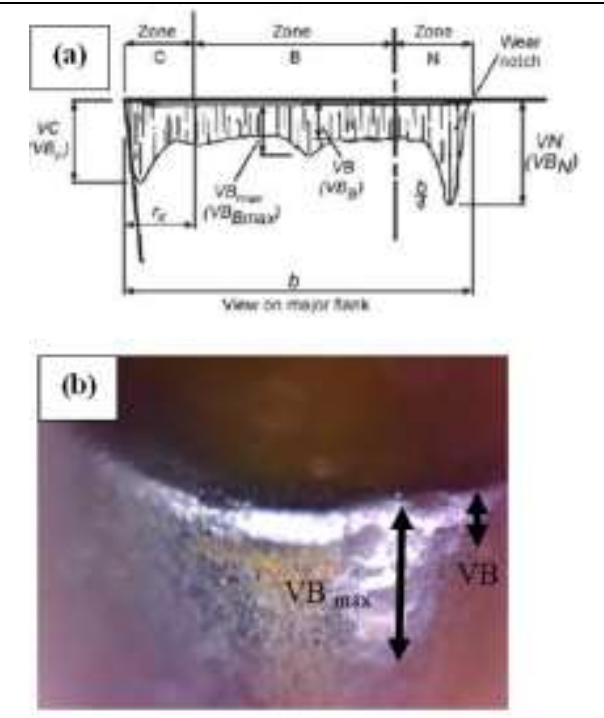

Fig. 10: Flank wear (a) typical flank wear [15] (b) resultant flank wear 


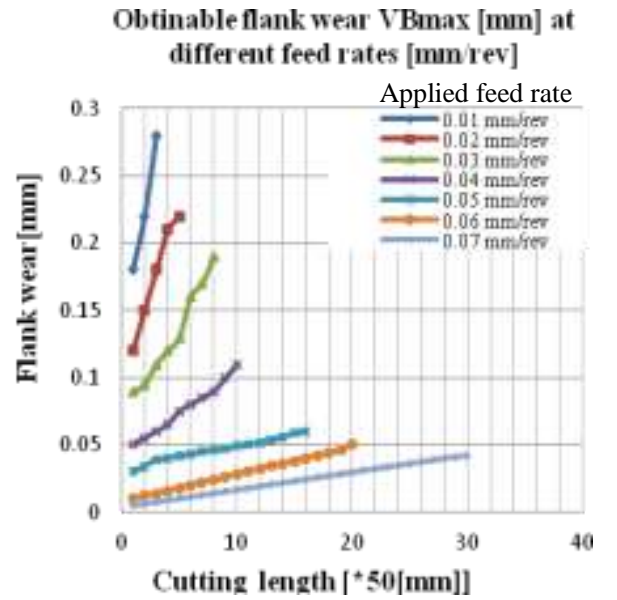

Fig. 11: Relation between Maximum flank wear value and cutting length at different feed rates

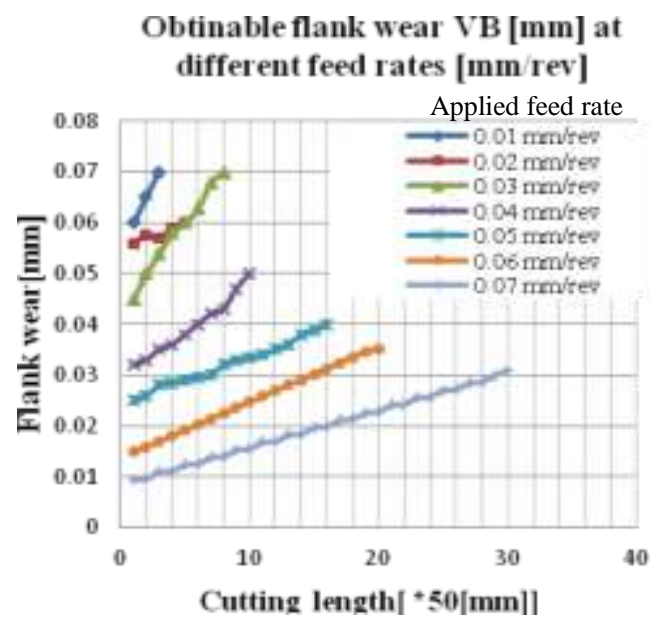

Fig. 12: Relation between flank wear value and cutting length at different feed rates

\subsection{Surface Roughness}

$\mathrm{Ra}$ values were measured over the machined surfaces after the first and the last passes to assess the roughness generated using new and worn tool, respectively. The roughness of the machined surface examined using a portable roughness tester as explained previously, where these measurements are illustrated in Fig. 13 against the applied cutting conditions for new and worn tools. From the results, it was observed that the surface roughness changes with the feed rate and conditions of the tool. However, when the feed rate was nearly equal $1: 1.5$ times the edge radius the best surface roughness obtained and this ration increase with the increase of machining length that reflect the effect of tool conditions, tool wear on the achievable roughness.

Feed rate $=(1: 1.5 \mathrm{re})$

where, re $=$ edge radius $=0.04 \mathrm{~mm}$

So the edge radius has a dominant effect on surface roughness in relation with feed rate. The curve reflect the trade-offs between the kinematic parameters and the minimum chip thickness effects. In particular, the improvement of the resulting surface roughness with the decrease of the feed rate from $0.06 \mathrm{~mm} / \mathrm{rev}$ to $0.04 \mathrm{~mm} / \mathrm{rev}$ is due to the effects of the kinematic factors such as the cutting parameters and the tool trajectories. Conversely, the roughness increase at feed rates below $0.03-0.04 \mathrm{~mm} / \mathrm{rev}$ can be explained with the effects of the minimum chip thickness. However, further reduction in the feed rate led to improvements in the surface finish which could be attributed to changes in the cutting mechanisms to burnishing not cutting.

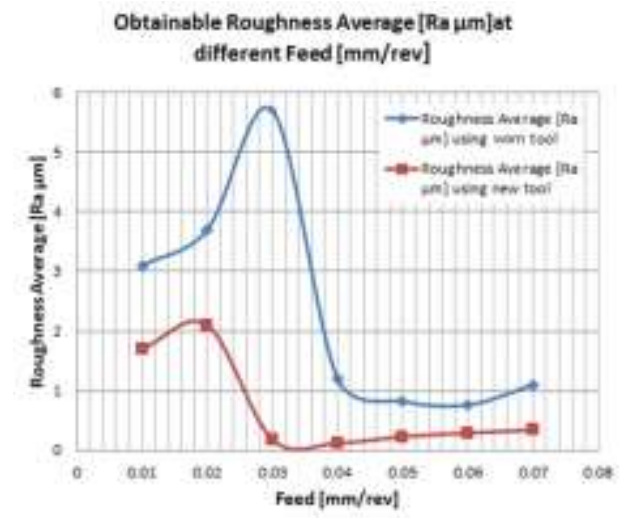

Fig. 13: Feed Rate and Surface Roughness Relation

\section{Conclusions}

This paper has reported on an investigation of tool wear and surface roughness during hard turning process of stainless steel 316. Seven sets of experimental tests were performed on a CNC turning machine with different feed 
rates. With the help of two digital microscopes photos were taken for flank and crater wear. From these photos the growth of the two types of tool wear was measured with software and curves were drawn to describe the relationship between tool wear and feed rates. After finishing the turning operation the surface roughness was measured to investigate the link between feed rate and surface roughness. The main conclusions can be drawn as follows:

-Crater wear happened in the tungsten carbide tools used in the experiments was a result for The most significant tool wear mechanism when cutting hard-to-cut materials which is diffusion because of high temperature along the tool-chip interface. This mechanism is the major reason crater wear. In this mechanism diffused particles transfer from the tool to the flowing chip and vice versa. These particles also carried away by the flow of chip-material along the tool-chip interface. The repetition of this process causes crater wear. This crater wear gradually becomes deeper with time, weakening of the tool tip; causing the failure of the cutting edge. The smaller feed rate causes higher wear rate while fixing other parameters and this relation illustrated with a curve. It was observed that the tool life also increased when the feed rate increased with the range of feed rates applied.

- Flank wear was measured at the seven sets of experiments. An inverse relationship between flank wear and feed rate revealed, this relation showed that flank wear increased with the decrease of feed rate and also the life time of the tool minimized with the rang of feed rates applied. A significant effect of cutting tool flank wear on the new machined surface quality also appeared. From the experiments the most important wear pattern in turning operation of hard-to-cut was flank wear and was mainly attributed to the abrasion mechanism.
-Surface roughness affected by feed rate and non-linear relationship between them was observed from the experiments. When the feed rate is equal nearly $1: 1.5$ times the edge radius the best surface roughness obtained, so the edge radius has an effect on surface roughness in relation with feed rate. The roughness increased at feed rates below $0.03 \mathrm{~mm} / \mathrm{rev}$ this can be explained with the effects of the minimum chip thickness However, further reduction in the feed rate led to improvements in the surface finish which could be attributed to changes in the cutting mechanisms.

From this investigation an important factor was revealed; this factor is the insert edge radius. The value of this radius played an important role in the cutting process to decide the most feed rate value, which gave the best surface roughness and the best tool wear optimization. So this value must be known before using the cutting insert especially at fine turning operations to get an accurate dimensions and best surface finish.

\section{Acknowledgments}

The reported research was partly funded by the Suez Canal Authority who deserves grateful thanks for providing technical and financial support to the authors to fulfill this research endeavor.

\section{References}

[1]. Yong Huang \& Y. Kevin Chou \& Steven Y. Liang: CBN Tool Wear in Hard Turning: a survey on research progresses, int $\mathrm{j}$ adv. Manuf. Technology(2007) 35:443-453 doi 10.1007/s00170-006-0737-6.

[2]. SThamizhmanii, K. Kamarudin, E. A. Rahim, A. Saparudin, S. Hassan: Tool Wear and Surface Roughness in Turning AISI 8620 Using Coated Ceramic Tool, proceedings of the world congress on engineering, London, U.K 2007 Vol II WCE, July $2-4$.

[3]. H.M. Lin a, Y.S. Liao b, C.C. Wei b: Wear Behavior in Turning High 
Hardness Alloy Steel by CBN Tool, wear 264 (2008) 679-684.

[4]. Xiaoyu Wang, Wen Wang, Yong Huang ,Nhan Nguyen, KalmanjeKrishnakumar: Design of Neural Network-based Estimator for Tool Wear Modeling in Hard Turning, $\mathrm{j}$ intell. manufacturing (2008) 19:383-396 DOI 10.1007/s10845-008-0090-8.

[5]. JinyangXu, Zhiqiang Liu, GuoqiangGuo, Ming Chen: An Investigation on Wear Mechanism of High-speed Turning of Free-cutting SteelAISI 1215Using Uncoated and Multi-layer Coated tools, int $\mathrm{j}$ adv. Manuf. Technology(2013) 67:517533 ,DOI 10.1007/s00170-012-45028.

[6]. Ali RizaMotorcu :Tool Life Performances, Wear Mechanisms and Surface Roughness Characteristics When Turning Austenised and Quenched AISI 52100 Bearing Steel With Ceramics and CBN/TiCCuttingTools , Indian journal of engineering \& materials sciences Vol. 18, April 2011, pp. 137-146.

[7]. Erol Bingul1 and Alaattin Kacal2: HardTurning of Powder Metallurgical Cold Work Tool Steel Tempered in Different Tempering Temperature, jo4u9rn8al of scientific \& industrial research 72 AUGUST 2013, Vol. 72, August 2013, pp. 498505.

[8]. YueCaixu, Liu Xianli, Ma Jing, Liu Zhaojing, liufei, and yang yongheng: Hardening Effect on Machined Surface For Precise Hard Cutting Process With Consideration of Tool Wear, Chinese journal of mechanical engineering vol. 27,ano. 6, a2014.

[9]. Alaattin Kaçal1, Ferhat Yıldırım2: High Speed Hard Turning of AISI S1
(60WCrV8) Cold Work Tool Steel ,ActaPolytechnica Hungarica Vol. 10, No. 8, 2013.

[10]. American iron and steel institutewebsite, URL:http://www.nickelinstitute.org/ /Media/Files/TechnicalLiterature/Stai nlessSteelsfor Machining_9011_.pdf, last access 28/6/2015.

[11]. Spectro website, URL: http://representatives.spectro.com/spe ctro-za/products/sma/lab11/, last access 29/6/2015.

[12]. SptechSystem,website,

URL:http://www.spsystem.com/main /products/pdisplay.php?active $=$ produ ct\&no=712\& thiscod.e $=1305$, last access 29/6/2015.

[13]. Jiang Hua, Rajiv Shivpuri :A cobalt Diffusion Based Model for Predicting Crater Wear of Carbide Tools in Machining Titanium Alloys . 1971 neil avenue, room 210, industrial, welding and systems engineering, the ohio state university,columbus, ohio 43210.

[14]. Map window website, URL:http://www.mapwindow.org/ last access 29/6/2015.

[15]. S.ThamizhmaniiandS.Hasan: Investigation of Surface Roughness and FlankWear by CBN and PCBN Tools on Hard Cr-Mo Steel, Proceedings of the World Congress on Engineering 2009 Vol IWCE, July 1 - 3, London, U.K.

[16]. Metrology world website, URL:http://www.metrologyworld.co m/doc/surface-roughness$\underline{\text { measurement-tester-0001, last access }}$ 27/6/2015.

[17]. MetalCuttingPhysics web site, URL: http://web.mit.edu/2.670/www/Tutori als/Machining/physics/Description.ht mllast access 29/6/2015. 